\section{Fixation and its role in the causation, laterality and location of pterygium: a study in amblyopes and non-amblyopes}

A Sudhalkar
M \& J Institute of Ophthalmology, Ahmedabad, India

Correspondence: A Sudhalkar, M \& J Institute of Ophthalmology, Ahmedabad, India Tel: +91265 279 3799; Fax: +912652420369. E-mail: adityasudhalkar@ yahoo.com

Received: 9 May 2011 Accepted in revised form: 3 November 2011 Published online: 9 December 2011

Presented as a free paper at ASCRS 2011, San Diego, CA, USA.

\section{Abstract}

Aim To evaluate the role of fixation in causing pterygium and determining its laterality and location.

Methods This is a prospective, observational, case-control study. Cases were defined as patients with primary pterygium who had unilateral amblyopia with eccentric fixation. Controls were age-matched patients with primary pterygium, but without amblyopia and eccentric fixation. All patients underwent complete ocular, orthoptic, and systemic examination and a detailed risk-factor assessment (latitude of residence, exposure to sunlight, sand, and a high-reflectance environment). The role of fixation in the causation, laterality and location of pterygium was evaluated. Fisher's exact test, the unpaired $t$-test, and odds ratio (OR) were carried out to determine the significance of the observations.

Results The mean age of subjects was $47.1 \pm 5.25$ years in cases $(n=107)$ and $48.2 \pm 4.75$ years in controls $(n=310 ; P=0.78)$. As far as known risk factors were concerned, both groups were evenly matched. Among the cases, $88(82.2 \%)$ patients demonstrated suppression of the amblyopic eye and $19(\mathbf{1 7 . 8 \%})$ patients had abnormal retinal correspondence (ARC). Patients with suppression had a unilateral pterygium in the better (fixating) eye, whereas those with ARC had bilateral pterygia. Among the controls, 192 (61.9\%) eyes had bilateral pterygia and 118 (38.1\%) eyes had unilateral pterygium. In controls, the dominant eye had a higher prevalence of pterygium. All patients in both groups had a nasal pterygium. Pterygium and fixation were strongly associated $(P=0.007$; Fisher's exact test; OR $-15.98 ; P=\mathbf{0 . 0 0 8}$ ). Conclusion Fixation appears to have an important role in causing pterygium and determining its location and laterality. Eye (2012) 26, 438-443; doi:10.1038/eye.2011.322; published online 9 December 2011

Keywords: pterygium; fixation; amblyopia

Introduction

A primary pterygium ${ }^{1,2}$ is a triangular, wingshaped, degenerative fibrovascular, hyperplastic proliferative tissue actively growing from the conjunctival limbal area (secondary probably to limbal cell damage) to the cornea. ${ }^{2}$ Although several studies deal with the etiology of this condition, ${ }^{3-10}$ the aetio-pathogenesis remains elusive. Although this is a bilateral condition, its development is often asymmetric, and tends to occur nasally commonly. ${ }^{1,2}$ One of the suggested hypotheses for the higher incidence of nasal pterygia is the reflection of light either from the nose or from the temporal orbital margin on to the nasal conjunctiva, ${ }^{1,2}$ leading to limbal stem cells and possibly inciting pterygium formation. Ocular dominance, eye closure in sunlight, divergence, corneal curvature, and anterior chamber depth are some of the other factors that may influence the laterality and location of pterygium. ${ }^{11-14}$ To the best of our knowledge, fixation has not been considered as an independent risk factor in any of the previous studies. We aimed to explore whether fixation (with subsequent focusing of sunlight on the nasal limbus leading to limbal stem cell damage) have a role in 
causing pterygium and in determining its location and laterality.

\section{Materials and methods}

This prospective, observational case-control study was conducted at the M \& J Institute of Ophthalmology, Ahmedabad, from May 2006 to May 2010. Informed consent was obtained from all patients. The Institute Review Board approved the study. The research methodology adhered to the tenets of Helsinki. Cases were defined as consecutive patients with: (a) unilateral amblyopia with eccentric fixation in the amblyopic eye $\mathrm{e}^{15}$ and (b) the presence of primary pterygium(gia). The diagnosis was made by an expert observer who was masked to the two groups and the objectives of the study.

Amblyopia is defined as a decrease in the visual acuity of one eye caused by abnormal binocular interaction. Amblyopia may also occur in one or both eyes as a result of pattern deprivation during visual immaturity, for which no cause can be detected during the physical examination of the eye(s). An expert, masked observer documented the presence of amblyopia: ${ }^{15}$ First a complete history of the patient was obtained (including a history of smoking/tobacco chewing/alcohol intake). Then a comprehensive examination was performed, which included: corrected distance visual acuity, refraction under the appropriate cycloplegic, the cover test (all components), a complete ocular examination including keratometry, slit lamp examination, corneal surface analysis, anterior chamber depth, gonioscopy, fundus examination, a complete orthoptic examination, including angle kappa measurements to rule out pseudoexotropia or pseudo-esotropia, and a complete systemic examination (to exclude neurologic or other systemic causes of decreased vision).

Eccentric fixation is known to occur in a subset of patients with amblyopia. ${ }^{15}$ It refers to the non-foveolar fixation pattern of the amblyopic eye when the better eye is covered and the patient asked to look at a fixed target (eg, the fixation disc of an ophthalmoscope). Eccentric fixation was documented using the fixation disc of the direct ophthalmoscope. Suppression is defined as the active central inhibition of disparate and confusing images originating from the retina of the deviated eye. ${ }^{1}$ Suppression was confirmed by Worth's four dot test and synoptophore examination, both for distance and near vision. Abnormal retinal correspondence (ARC) is a form of sensorial adaptation wherein the fovea of the normal fixating eye acquires a common visual direction with a peripheral element in the deviated eye. ${ }^{15}$ The presence of ARC was determined with the help of the Worth's four dot test, Bagolini's striated glasses, and the synoptophore (Clement Clarke Int., Harlow, UK). The eye that maintains fixation at the near point of convergence is generally considered to be the dominant eye, and the deviating eye is the non-dominant eye. ${ }^{15}$ Ocular dominance was confirmed by the Royal Air Force rule test. Controls consisted of consecutive patients from the same age bracket as cases, with pterygium(gia), but without amblyopia and eccentric fixation. They underwent the same examination protocol as the cases.

Both groups were assessed with regard to the major risk factors identified by McKenzie et al. ${ }^{10}$ These risk factors were determined with reference to the patients' lifestyle and working habits. The goal was to establish whether exposure to known risk factors was comparable in both groups.

\section{Solar exposure}

Threlfall and English ${ }^{6}$ have prepared a questionnaire to determine the extent of ocular solar exposure. This questionnaire was adapted for Indian climatic conditions, to establish whether ocular solar exposure was comparable in both groups. Briefly, it involves a detailed analysis using the Kricker ${ }^{16-18}$ questionnaire on solar exposure, the time spent outdoors in peak sunshine hours, the use of protective eyewear, the time spent in sunlight on non-working days or vacation periods, and so on. These factors are taken into account along with the solar radiation pertinent to a particular region (in this study: Gujarat, Western India) ${ }^{18-20}$ and the total ocular solar radiation dose determined. Ocular solar exposure was calculated at a year-of-life level as the product of exposure hours, intensity adjustment factor, and duration adjustment factor. This was then considered over a period of 15 years in both cases and controls, as asymmetric development of pterygium is a known fact. ${ }^{1,2}$ All patients in both groups resided between latitudes $20^{\circ} 36^{\prime} \mathrm{N}$ and $22^{\circ} 10^{\prime} \mathrm{N}$ (Western India). The daily average solar energy incident varies from 6.5 to $7 \mathrm{kWh} / \mathrm{m}^{2}$ in this region depending on the exact location within these provinces. ${ }^{19-21}$ The annual average global solar radiation on the horizontal surface incident over India is about $5.5 \mathrm{kWh} / \mathrm{m}^{2} /$ day. $^{20}$ The region of Western India from which these patients were recruited has an average of 300 sunny days/year.

\section{High-reflectance outdoor environment}

Working in an environment with a high surface reflectance of ultraviolet light (eg, amidst concrete buildings; specifically: outdoor work) has been shown to increase the risk of pterygium occurrence several fold. ${ }^{10}$ A method similar to that adopted by McKenzie et $a l^{10}$ was used to determine the duration of exposure to such 
an environment in terms of the time spent in and away from such a setting over a 15-year period.

\section{Sand}

Professional or residential exposure to sand has been shown to increase the risk of pterygium several times, ${ }^{10}$ however, none of the subjects in either group came from sandy/desert provinces, nor were they involved in the use of sand professionally (eg, construction workers); nor was their residence in the vicinity of a sandy area. Thus this factor was automatically matched in both groups.

In addition, all the patients in cases and controls were specifically asked whether they had a habit of closing a particular eye while working in sunlight (a phenomenon known to be conscious and voluntary ${ }^{15,22,23}$ ). Details were elicited regarding the duration of eye closure in sunlight, viz. momentary or prolonged. The outcome measure was determination of the laterality and location of pterygium (pterygia) in patients of both groups. The Fisher's exact test and odds ratio (OR) were computed, keeping in mind that 'fixation' was hypothesised to be a 'risk factor' for pterygium formation (Table 1). The peripheral corneal curvature, keratometry values, and anterior chamber depth were compared using the unpaired $t$-test to determine whether there was any difference between eyes with and without pterygium. Statistical analysis was carried out using the SPSS $^{24}$ version 16 software. Statistical significance was set at a level of $P<0.01$.

\section{Results}

The mean age of patients among the cases $(n=107$ patients) was $47.1 \pm 5.25$ years with a range from 40 to 60 years. The mean age among the controls $(n=310$ patients) was $48.2 \pm 4.75$ years with a range from 41 to 59 years. Both groups were matched with respect to age $(P=0.78$, unpaired $t$-test $)$.

The most common presenting complaint in both groups was visual and/or cosmetic disturbance. Three patients in the control group reported that pterygium had been present in the father. The father in all the three

Table 1 Pterygium in cases and controls; distribution as per the fixating/non-fixating eye

\begin{tabular}{lccc}
\hline Groups & $\begin{array}{c}\text { Pterygium } \\
\text { present }\end{array}$ & $\begin{array}{c}\text { Pterygium } \\
\text { absent }\end{array}$ & $\begin{array}{c}\text { Total } \\
(\mathrm{n})\end{array}$ \\
\hline $\begin{array}{l}\text { Fixating eye/dominant eye } \\
\text { Non-fixating eye/non-dominant } \\
\text { eye }(n)\end{array}$ & 397 & 20 & 417 \\
Total & 231 & 186 & 417 \\
\hline
\end{tabular}

Abbreviation: $n$, number of eyes. cases had a similar work history. A detailed history failed to reveal habitual eye closure for long periods ( $>10 \mathrm{~min}$ of the time spent outdoors) in sunlight in any of the 417 recruited patients. Of these, 176 patients reported that eye closure occurred momentarily, when they stepped into bright sunlight from a dark environment, and this amounted to $<10 \mathrm{~min} /$ day. The mean duration of unilateral pterygium in cases and controls was not significantly different $(84.25 \pm 7.50$ vs $82.50 \pm 13.25$ months, $P=0.28$ ). Four patients in the cases and three in the control group had a stationary pinguecula in the other eye since an average of $11.34 \pm 1.23$ years.

The average daily ocular solar radiation dose was not significantly different between cases and control $\left(247.23 \pm 23.12 \mathrm{mWh} / \mathrm{cm}^{2}\right.$ vs $241.3 \pm 20.21 \mathrm{mWh} / \mathrm{cm}^{2}$, $P=0.2)$. The average corrected number of hours spent per day in a high-reflectance (amidst concrete buildings) environment was also not significantly different between cases and controls $(14.25 \pm 0.75$ and $13.25 \pm 0.50 \mathrm{~h}$, respectively, $P=0.274$ ). The cases and controls were found to be matched for duration of pterygium, exposure to sunlight, concrete, and sand. Moreover, all cases and controls came from approximately the same age bracket and latitudinal zones. There was no significant difference in keratometry values and peripheral corneal curvature in eyes with and without pterygium $(P=0.12)$. The anterior chamber depth did not vary significantly in eyes with and without a pterygium $(P=0.2)$ (Figures 1 and 2).

In the cases group, there were 70 males and 37 females. These patients had unilateral amblyopia with eccentric fixation, with the amblyopic eye in exotropia in 90 cases and in esotropia in 17 cases. The mean corrected distance visual acuity in the amblyopic eyes was $2.0 \pm 1.0 \mathrm{log}$ MAR units with a range of 1.0-3.0 log MAR units. The mean corrected distance visual acuity in the

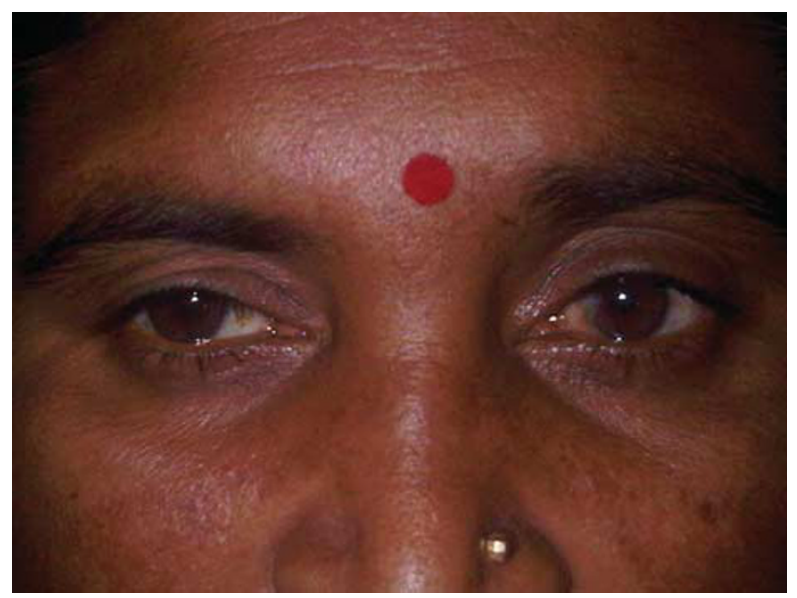

Figure 1 A patient from the case group who had unilateral pterygium in the fixating eye, with the other eye amblyopic and in exotropia. 


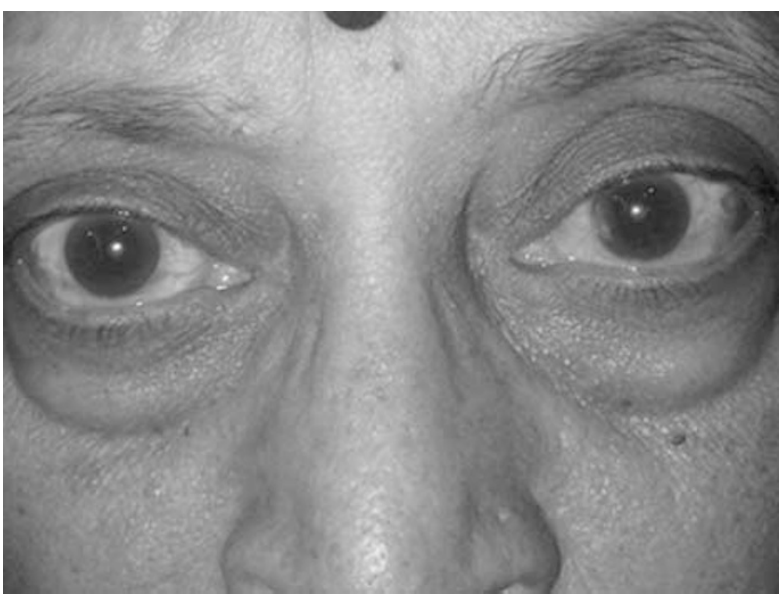

Figure 2 A patient from the control group who had unilateral pterygium but no amblyopia and eccentric fixation.

non-amblyopic eyes was $0.3 \pm 0.17 \log$ MAR units with a range of $0.0-0.40 \log$ MAR units. The range of deviation in both exotropes and esotropes was $7^{\circ}$ to $>60^{\circ}$. In all, 88 patients $(82.4 \%)$ showed suppression of the amblyopic eye and 19 patients showed the presence of ARC. Thus, 88 patients $(82.4 \%)$ had monocular vision under binocular conditions (suppression) and 19 patients (17.8\%) had binocular vision despite the presence of a deviation. In all, 58 patients had strabismic amblyopia, 27 patients had mixed anisometropia and strabismus, 18 patients had anisometropic amblyopia, and 4 patients had occlusion amblyopia. All cases demonstrating suppression of the amblyopic eye had a unilateral pterygium in the fixating eye. The 19 cases with ARC had bilateral pterygia. The development of pterygium in all the 19 patients was asymmetric, with the deviated eye affected initially in 10 patients and the better eye in 9 .

The control groups had 217 males and 93 females. The mean corrected distance visual acuity (both eyes) was $0.4 \pm 0.2 \log \mathrm{MAR}$, with a range of 0.0 to $\mathrm{HM}+$ (hand motions at $33 \mathrm{~cm}$, other eye closed), PL + (perception of light at $33 \mathrm{~cm}$, other eye closed), and PR4 + (projection of rays, all four quadrants at $33 \mathrm{~cm}$, other eye closed). There was one patient with $\mathrm{HM}+\mathrm{PL}+\mathrm{PR} 4+$ vision in one eye, which had a mature cataract and $0.5 \log$ MAR BCVA in the other eye with pterygium in both eyes. The eye with the mature cataract did not have any history of decreased vision since childhood. In the controls, 192 eyes (61.9\%) had a bilateral pterygia and 118 eyes (38.1\%) had unilateral pterygium. Among the patients with bilateral pterygia, the dominant eye was affected first in 165 patients $(85.94 \%)$. Among those with unilateral pterygium, the dominant eye was affected in 98 patients $(83.1 \%)$. This was confirmed by noting down a detailed history of the patients and carrying out an examination of ocular dominance.
Table 2 Distribution of pterygium in the case groups

\begin{tabular}{lccc}
\hline & $\begin{array}{c}\text { Pterygium } \\
\text { present }\end{array}$ & $\begin{array}{c}\text { Pterygium } \\
\text { absent }\end{array}$ & $\begin{array}{c}\text { Total } \\
(\mathrm{n})\end{array}$ \\
\hline $\begin{array}{l}\text { Non-amblyopic } \\
\text { (better) eye }\end{array}$ & 107 & 0 & 107 \\
$\begin{array}{l}\text { Amblyopic eye } \\
\text { Total }(n)\end{array}$ & 19 & 88 & 107 \\
\hline
\end{tabular}

Abbreviation: $n$, number of eyes.

${ }^{a}$ Overall, 19 cases had ARC and had a pterygium in the amblyopic eye as well.

${ }^{\mathrm{b}}$ The better eye was the only fixating eye in 88 cases; the remaining cases had both eyes fixating.

Table 3 Distribution of pterygium as per ocular dominance in the control group

\begin{tabular}{lccc}
\hline & $\begin{array}{c}\text { Pterygium } \\
\text { present }\end{array}$ & $\begin{array}{c}\text { Pterygium } \\
\text { absent }\end{array}$ & $\begin{array}{c}\text { Total } \\
(\mathrm{n})\end{array}$ \\
\hline Dominant eye $(n)$ & 290 & 20 & 310 \\
Non-dominant eye $(n)$ & 212 & 98 & 310 \\
Total $(n)$ & 502 & 118 & 620 \\
\hline
\end{tabular}

Abbreviation: $n$, number of eyes.

Out of the 118 controls with unilateral pterygium, 32 patients had intermittent exotropia, 24 of the divergence excess type, and 8 of the convergence insufficiency type. During testing, the dominant eye maintained fixation for a greater period of time as compared with the non-dominant eye. All these 32 patients showed good control on the deviation, as judged by the Newcastle score for intermittent exotropia, and all had a pterygium in the dominant eye.

The OR (cases and controls), keeping in mind that fixation was a 'risk factor' for pterygium, was 15.98 ( $P=0.008$; Table 1). The Fisher's exact test returned a probability value of $P=0.007$ (Table 1 ). Thus the fixating eyes were at a significantly higher risk of incurring pterygium. Table 2 shows the distribution of pterygium occurrence in cases with respect to the amblyopic and non-amblyopic eye and the OR for this distribution returned a highly significant value $(\mathrm{OR}=29.39$; null hypothesis approach; $P<0.001$ ). Table 3 shows the distribution of pterygium occurrence in the control group with respect to ocular dominance $(\mathrm{OR}=6.70 ; P=0.008)$.

Pterygia in cases and controls, whether unilateral or bilateral, were on the nasal side. None of the patients had a temporal pterygium.

The results show that the dominant eye/fixating eye seems to be at a higher risk of developing pterygium.

\section{Discussion}

As stated by Noorden et al, ${ }^{15}$ eccentric fixation is a characteristic of a subset of amblyopic patients, 
irrespective of whether the person had exotropia or esotropia in the developmental period (ie, up to the age of 7-8 years). Also, spontaneous secondary exotropia (and very rarely, esotropia) in a long-standing amblyopic eye is a known occurrence. ${ }^{15,25,26}$ Hence, it may be difficult to determine whether a person was a unilateral esotrope or exotrope to begin with. The eye with eccentric fixation is generally suppressed as an adaptive measure under binocular conditions; hence, these patients fixate monocularly. ARC refers to another form of sensorial adaptation wherein the fovea of the normal eye develops an intimate, binocular relationship with an extra-foveal point of the deviated eye. These patients fixate binocularly in spite of the presence of a deviation and may have some degree of stereopsis as well. ${ }^{15}$

During outdoor work, the entire palpebral fissure is bilaterally exposed to sunlight. However, pterygium formation is more common nasally. On the other hand, pterygium is uncommon in divergent eyes, even though a greater part of the nasal conjunctiva is exposed to sunlight. Coroneo ${ }^{9}$ has sought to explain this discrepancy through his suggestion of transcameral focusing and subsequent concentration (up to 20 times) of the albedo ultraviolet light from the temporal limbus on to the nasal limbus, which also happens to be the most common site for pterygium formation. Fixation possibly provides a continuous and focused concentration of ultraviolet light on to the nasal limbus in patients with prolonged exposure to sunlight. This probably leads to limbal stem cell damage and subsequent pterygium formation. ${ }^{7-10}$ The current study seems to indicate that the presence of other risk factors does not appear to be sufficient to initiate pterygium formation as long as fixation is absent. This study also suggests that decreased vision and/or ocular deviation do not preclude an eye from pterygium formation (contrary to Saad ${ }^{12}$ ), unless it implies a concurrent loss of the ability to fixate as well. For instance, in this study, although patients with ARC had decreased vision in and deviation of one eye, they had bilateral pterygia.

Although past authors have speculated on the reasons for a paucity of temporal pterygia, $, 8,9,27-30$ we cannot comment on the same as we did not encounter any case of temporal pterygium in our study.

In this study, we did not find a single patient who reported long periods of closure of one eye while working. If it did occur, it was momentary, not exceeding $10 \mathrm{~min} /$ day. It is well known that this type of eye closure is voluntary and does not occur without the patient's knowledge. ${ }^{15,22,23}$ Eustace et $a l^{23}$ and Wirtschafter and Burassa $^{24}$ have suggested that intense sunlight disrupts fusion and subsequently leads to exotropia in susceptible individuals (eg, intermittent exotropes), thereby leading to monocular fixation. Nearly one-third of the eyes in the control groups with unilateral pterygium had intermittent exotropia, which was probably disrupted by sunlight, leading to monocular fixation with the dominant eye. However, the dynamics of bi-foveal fixation, its intermittent interruption by sunlight, and the effect thereof on constant limbal focusing of ultraviolet rays need further investigation. Other factors, such as anterior chamber depth and keratometry values, did not vary significantly in this study between eyes with and without a pterygium.

This study thus provided three subsets for comparison: (1) Intra-observer, in the cases group, between the fixating and non-fixating eye, thus comparing two eyes of the same individual. (2) Within the cases group, between patients with suppression of the amblyopic eye and patients with ARC. (3) Between cases and controls.

In all the three subsets, pterygium either developed solely in the eye which fixated or developed first in most instances in the eye that maintained fixation for a major part of the time spent exposed to risk factors. In conclusion, we would like to state that fixation appears to have a central role in the causation, laterality, and location of pterygium.

\section{Summary}

What was known before

- Ultraviolet light is concentrated via the intracameral pathways from the temporal to the nasal limbus in pterygium formation. This does not occur the other way round, probably because of the nose and superior orbital rim obstructing the light pathways.

What this study adds

- Fixation is the only factor that provides a steady, focused dose of ultraviolet light to the limbus by previously described mechanisms, akin to a magnifying glass held steadily over a piece of paper. A non-fixating eye can be likened to a magnifying glass held defocused over a paper.

\section{Conflict of interest}

The author declares no conflict of interest.

\section{References}

1 Foster CS, Azar DT, Dohlman CH. The Cornea: Scientific Foundations and Clinical Practice, 4th ed. Lippincott Williams and Walters: Philadelphia, PA, 2005.

2 Yanoff M, Duker JS. Ophthalmology, 2nd ed. Elsevier Publications: Philadelphia, PA, USA, 2008.

3 Buratto L, Phillipe RL, Carito G. Pterygium Surgery Chapter on. SLACK Incorporated, Thorofare Publications: New Jersey, NJ, 2000.

4 Saw SM, Tan D. Pterygium: prevalence, demography and risk factors. Ophthalmic Epidemiol 1999; 6: 219-228. 
5 Reid TW, Dushku N. Does human papillomavirus cause pterygium? Br J Ophthalmol 2003; 87: 806-808.

6 Threlfall TJ, English DR. Sun exposure and pterygium of the eye: a dose-response curve. Am J Ophthalmol 1999; 128: $280-287$.

7 Sekelj S, Dekaris I, Kondza-Krstonijević E, Gabrić N, Predović J, Mitrović S. Ultraviolet light and Pterygium. Coll Antropol 2007; 31(1): 45-47.

8 Soliman Mahdy MA, Bhatia J. Treatment of primary pterygium: role of limbal stem cells and conjunctival autograft transplantation. Eur J Ophthalmol 2009; 19(5): 729-732.

9 Coroneo MT. Pterygium as an early indicator of ultraviolet insolation. Br J Ophthalmol 1993; 77: 734-739.

10 Mackenzie FD, Hirst LW, Battistutta D, Green A. Risk analysis in the development of pterygia. Ophthalmol 1992; 99: 1056-1061.

11 Jensen OL. Pterygium, the dominant eye and the habit of closing one eye in sunlight. Acta Ophthalmol (Copenh) 1982; 60: $568-574$.

12 Saad R. Pterygium, pinguecula and visual acuity. Aust J Ophthalmol 1977; 5(1): 52-65.

13 Maloof AJ, Ho A, Coroneo MT. Influence of corneal shape on limbal light focusing. Invest Ophthalmol Vis Sci 1994; 35: 2592-2598.

14 Cullen AP. Anterior eye focusing of peripheral ultraviolet and visible albedo. Clin Exp Optom 1997; 80(3): 80-86.

15 Noorden GK, von Campos E. Binocular Vision and Ocular Motility, 6th ed., Chapter 14. Mosby Publishers: Maryland Heights, MO, USA, 1999, pp 246-293.

16 Kricker A, Armstrong BK, Parkin DM. Measurement of skin cancer incidence. Health Rep 1993; 5: 63-66.

17 Rosenthal FS, Bakalian AE, Taylor HR. The effect of prescription eyewear on ocular exposure to ultraviolet radiation. Am J Public Health 1986; 76: 1216-1220.

18 Taylor HR, West SK, Rosenthal FS, Munoz B, Newland HS, Emmett EA. Corneal changes associated with chronic UV irradiation. Arch Ophthalmol 1989; 107: 1481-1484.
19 Landsberg HE. World Survey of Climatology. Elsevier: Amsterdam, 1984.

20 Ministry of New and Renewable Energy-Official Website (Government of India data). mnre.gov.in/spv-intro.htm.

21 Indian Institute of Sciences. CEDT. Solar irradiance. http:/ /ecourses.vtu.ac.in/nptel/courses/Webcourse-contents/ IISc-BANG/Non-Conventional\%20Energy\%20Systems/pdf/ chap03.pdf.

22 Argyrous G. Statistics or Research: With a Guide to SPSS, 2nd ed. SAGE: London, 2005.

23 Eustace P, Wesson ME, Drury DJ. The effect of illumination on intermittent divergent squint of the divergence excess type. Trans Ophthalmol Soc UK 1973; 93: 559-570.

24 Wirtschafter JD, Burassa CM. Effect of increasing illumination on exodeviations. Invest Ophthalmol 1964; 3: 549 .

25 Stidwill D. Orthoptic Assessment and Management, 2nd ed., Chapter 8. Blackwell Science: Oxford, UK, 1998, pp 140-149.

26 Wang Y, Liang YB, Sun LP, Duan XR, Yuan RZ, Wong TY et al Prevalence and causes of amblyopia in a rural adult population of Chinese- the Handan Eye Study. Ophthalmology 2011; 118: 279-283.

27 Attebo K, Mitchell P, Cumming R, Smith W, Jolly N, Sparkes R. Prevalence and causes of amblyopia in an adult population. Ophthalmol 1998; 105: 154-159.

28 Coroneo MT, Müller-Stolzenburg NW, Ho A. Peripheral light focusing by the anterior eye and the ophthalmohelioses. Ophthalmic Surg 1991; 22: 705-711.

29 Coroneo MT. Albedo concentration in the anterior eye: a phenomenon that locates some solar diseases. Ophthalmic Surg 1990; 21: 60-66.

30 Detorakis ET, Spandidos DA. Pathogenetic mechanisms and treatment options for ophthalmic pterygium: trends and perspectives (Review). Int J Mol Med 2009; 23: 439-447.

31 Chui J, Di Girolamo N, Wakefield D, Coroneo MT. The pathogenesis of pterygium; current concepts and their therapeutic implications. Ocul Surf 2008; 6: 24-43. 